\title{
Complications in a contemporary series of patients who underwent transsphenoidal surgery for Cushing's disease
}

Patrick L. Semple, F.C.S.(SA), M.Med., and Edward R. Laws, Jr., M.D.

Department of Neurosurgery, University of Cape Town, Cape Town, South Africa; and Department of Neurological Surgery, University of Virginia Health Sciences Center, Charlottesville, Virginia

Object. Transsphenoidal surgery is the usual treatment of choice for adrenocorticotropic hormone-secreting pituitary adenomas associated with Cushing's disease. In this paper the authors investigate the complications of transsphenoidal surgery in the treatment of a contemporary series of patients with Cushing's disease.

Methods. Between January 1992 and December 1997, 105 patients with Cushing's disease underwent transsphenoidal surgery at the University of Virginia Health Sciences Center. A retrospective analysis of the complications was conducted, and the mortality rate was found to be $0.9 \%$ and permanent morbidity was $1.8 \%$. The overall number of complications was 14 (13.3\%), which included seven complications directly related to surgery; one instance of permanent diabetes insipidus; one syndrome of inappropriate secretion of antidiuretic hormone; and five medical complications (four patients developed deep vein thrombosis and one developed pneumonia).

Conclusions. Transsphenoidal surgery for Cushing's disease has a higher complication rate than that for pituitary adenomas in general. This is primarily related to a greater number of medical complications, most notably deep vein thrombosis, resulting from the generally debilitated state of most patients with Cushing's disease. In view of the high incidence of deep vein thrombosis in these patients, prophylaxis for thromboembolism during the perioperative period is recommended.

Key Words * Cushing's disease * transsphenoidal surgery * complications * deep vein thrombosis

Over the last three decades, transsphenoidal surgery has become established as the primary therapy of choice for Cushing's disease.[2,3,12,13,15] Although it has potentially serious complications, in the hands of experienced surgeons it is a safe procedure with a mortality rate of less than $1 \% .[3,6,11]$ Patients with Cushing's disease often have associated medical problems such as obesity, hypertension, and diabetes that increase the risk associated with surgery. However, because most of these patients are relatively young and their pituitary tumors are usually small, it is somewhat less likely that they will suffer from complications of the surgery itself.[12] The aim of this study was to determine whether complications from transsphenoidal surgery in patients with Cushing's disease were comparable to those in more generalized series of patients treated for pituitary adenomas of all types. 


\section{CLINICAL MATERIAL AND METHODS}

At the University of Virginia Health Sciences Center between January 1992 and December 1997, 105 consecutive patients with Cushing's disease underwent surgery via the transsphenoidal route. There were 22 male and 83 female patients, whose mean age was 38.5 years (range 6-78 years). Central adrenocorticotropic hormone-dependent Cushing's disease was diagnosed using endocrinological function tests in all patients, and if the tests had been performed at another institution the results were verified by the endocrinologists at the University of Virginia Health Sciences Center. Twenty-seven patients had recurrent disease for which they had previously undergone surgery: 21 elsewhere and six at our institution. Magnetic resonance (MR) imaging of the pituitary fossa was performed in all cases. Preoperative diagnoses were in 74 patients with microadenomas and 13 with macroadenomas; 18 had normal imaging studies (Table 1).

\begin{tabular}{|cc|}
\hline \multicolumn{2}{|c|}{ TABLE 1 } \\
CHARACTERISTICS OF PATIENTS UNDERGOING TRANSSPHENOIDAL SURGERV \\
FOR CUSHING'S DISEASE
\end{tabular}

A single surgeon (E.L.) performed each surgery by using the sublabial or endonasal route. Nafcillin or vancomycin were administered prophylactically during the operative procedure. Elastic stockings were utilized intraoperatively and throughout the patients' hospital stay. Pneumatic compression devices were not used, nor were low-dose heparin therapy or routine lower-extremity vascular Doppler studies. Later in the series, patients with Cushing's disease were started on aspirin therapy ( $81 \mathrm{mg} /$ day) on the 1st postoperative day.

The patients were monitored postoperatively by using clinical and biochemical methods, with particular attention to fluid balance. A routine noncontrast-enhanced computerized tomography (CT) scan was obtained the day after surgery, and the nasal packing was removed 12 to 48 hours postsurgery. Hydrocortisone therapy was not given during or after surgery; however, if patients developed signs and symptoms of adrenal insufficiency and had a serum cortisol level of less than $3 \mu \mathrm{g} / \mathrm{dl}$ they received maintenance hydrocortisone replacement therapy. Patients with no complications were discharged on the 3rd day postsurgery and received follow-up care in our pituitary clinic. Most patients in whom remission of disease was achieved required hydrocortisone therapy for many months.

A retrospective analysis of the patients was conducted. Criteria for remission of Cushing's disease in the 
immediate postoperative period included a decrease in cortisol levels to subnormal amounts and the need for cortisol replacement therapy (Table 2).

\begin{tabular}{|c|c|c|}
\hline \multicolumn{3}{|c|}{$\begin{array}{c}\text { TABLE } 2 \\
\text { REMISSION OF CUSHING'S DISEASE AF TER TRANSSPHENOIDAL } \\
\text { SURGERY IN } 105 \text { PATIENTS }\end{array}$} \\
\hline Group & No. of Cases & Percentage \\
\hline $\begin{array}{l}\text { Patients overall } \\
\text { primary ops for microadenoma } \\
\text { macroadenomas \& reops }\end{array}$ & $\begin{array}{l}79 \text { of } 105 \\
64 \text { of } 72 \\
15 \text { of } 33\end{array}$ & $\begin{array}{l}75.2 \\
88.9 \\
45.5\end{array}$ \\
\hline
\end{tabular}

\section{RESULTS}

As shown in Table 3, 14 patients (13.3\%) developed a complication, and one patient died (0.9\%). The average age of the patients with complications was 39.9 years, and the ratio of women to men was 3.4:1, which is similar to the overall series of patients with Cushing's disease. Only one of the patients who developed a complication had undergone previous transsphenoidal surgery, and the patient who died had previously been treated medically and with gamma knife radiosurgery. According to neuroradiological findings, five patients who developed a complication had microadenomas, four had macroadenomas, and five had normal MR images.

\begin{tabular}{|c|c|c|c|c|c|}
\hline \multicolumn{6}{|c|}{$\begin{array}{c}\text { TABLE } 3 \\
\text { COMPL CATIONS IN A CONTEMPORARV SER ES OF TRANSS PHENODAL SURGERV FOR } \\
\text { CUSHNG'S DISEASE* }\end{array}$} \\
\hline $\begin{array}{l}\text { Case } \\
\text { No. }\end{array}$ & $\begin{array}{l}\text { Age (ys) } \\
\text { Sex }\end{array}$ & $\begin{array}{l}\text { Previous } \\
\text { Treatment }\end{array}$ & $\begin{array}{c}\text { MRI } \\
\text { Findngs }\end{array}$ & $\begin{array}{l}\text { Irva- } \\
\text { sion }\end{array}$ & Complication \\
\hline 1 & $24, F$ & - & micro & no & permanent $\mathrm{DI}$ \\
\hline 2 & 48, M & $\operatorname{trans\dagger }$ & macro & no & perforation \\
\hline 3 & $52, \mathrm{~F}$ & - & macro & yes & rom bosis \\
\hline 4 & $32, \mathrm{~F}$ & - & micro & yes & CSF rhinorrea (postop) \\
\hline 5 & $52, M$ & - & normal & no & hrom bosis \\
\hline 6 & $37, \mathrm{~F}$ & - & normal & no & ocul \\
\hline 7 & $53, M$ & - & micro & yes & deep wein throm bosis \\
\hline 8 & $68, F$ & Gk† & normalf & no & $\begin{array}{l}\text { SIд DH, hyponatremia } \\
\text { (fatal) }\end{array}$ \\
\hline 9 & $71, F$ & - & micro & - & pneum onia \& UTI \\
\hline 10 & $36, F$ & - & macro & yes & hrombosis \\
\hline 11 & 28, F & - & micro & no & epistaxi \\
\hline 12 & $45, F$ & - & macro & yes & $\begin{array}{l}\text { 3rd cranial ner'e palsy' } \\
\text { (transient) }\end{array}$ \\
\hline 13 & $32, F$ & - & normal & no & nasal septal perforation \\
\hline 14 & $47, M$ & - & normal & no & wound dehiscence \\
\hline \multicolumn{6}{|c|}{$\begin{array}{l}\text { * All adenomas presum ed from MR findings were confirmed on pathological ex- } \\
\text { amination, exoept in Case } 9 \text {. Abbre viations: Gk = Gam ma knife; invasion = inva- } \\
\text { sion of dura seen on pathological exam ination; macro = macroadenoma; micro = } \\
\text { microadenom a; trans = transsphenoidal UTI = urinary tract infection; - = none. } \\
\dagger \text { These procedures were performed at another institution. } \\
\text { † Normal pituitary gland according to pathological exam ination. }\end{array}$} \\
\hline
\end{tabular}

\section{Fluid Homeostasis}

Diabetes insipidus (DI) developed postoperatively in 10 patients. Seven cases of DI developed in the first 
48 hours postoperatively, were transient in nature, and were corrected by a single dose of desmopressin. Two patients developed delayed DI, at 2 weeks and 1 month postoperatively, respectively. Their DI was transient in nature and required a short course of desmopressin. We did not regard these cases as complications. Delayed onset, permanent DI requiring hormone replacement therapy occurred in one patient 2 months postoperatively.

Six patients developed hyponatremia in this series; in five cases it occurred during the immediate postoperative period (48 hours) and was transient, resolving after fluid intake was restricted. These patients were not included in the group with complications. Symptomatic hyponatremia occurred 2 months postoperatively in one elderly patient who had presented at another institution with obtundation and a serum sodium level of $107 \mathrm{mg} / \mathrm{dl}$; she showed no signs of meningitis. She developed fatal central pontine myelinolysis after rapid correction of her hyponatremia and was the sole death in this series. It is possible that delayed syndrome of inappropriate secretion of antidiuretic hormone (SIADH) and cortisol deficiency played a role in her death. There was no evidence of delayed cerebrospinal fluid (CSF) rhinorrhea, pneumocephalus, or meningitis.

\section{Complications Related to Surgery}

Seven patients had complications specifically related to the surgical procedure. In one patient, permanent unilateral ocular neuropathy with no subsequent visual improvement occurred as a result of a misdirected approach. The postoperative CT scan did not reveal a fracture of the optic canal and the injury was presumed to be related to direct contusion of the optic nerve or vasospasm. In another patient, early reoperation and packing of the sphenoid sinus with fat was used to control postoperative CSF rhinorrhea. One patient with a macroadenoma developed a transient third cranial nerve palsy, presumably related to removal of tumor from the cavernous sinus. A CT scan demonstrated no intracranial disease and the third cranial nerve function returned to normal during the following 3 days. Epistaxis occurred 3 weeks after surgery in a single patient, requiring cauterization of the sphenopalatine artery. There were two patients with nasal septal perforations seen on postoperative follow-up images, but both were asymptomatic. These patients had mucosal tears noted at the time of surgery, and an attempt was made to repair these tears during closure; neither of these patients had overt diabetes mellitus. Finally, dehiscence of the abdominal fat graft site developed in one patient.

\section{Nonsurgery-Specific Complications}

Deep vein thrombosis occurred in four patients between 2 weeks and 1 month postsurgery. Greenfield filters were placed in two patients, and all four were successfully managed with coumadin therapy. No pulmonary embolus occurred.

Pulmonary and urinary tract infections requiring intravenously administered antibiotic drugs occurred in an elderly patient 1 week postsurgery.

\section{Remission of Cushing's Disease}

The entire series of 105 patients included 27 patients who underwent reoperation and a number of patients who had deviations from the ideal preoperative laboratory values, which led to a diagnosis of adrenocorticotropic hormone-dependent Cushing's disease. These results are partially due to the status of our practice as a referral center for difficult cases. In the immediate postoperative period, disease in 79 patients $(75.2 \%)$ was in remission and in $26(24.8 \%)$ it was not. If the 27 secondary procedures and the 16 macroadenomas (seven also included in secondary procedures and six in primary) are considered 
separately because of anticipated suboptimal results, a remission rate of $88.9 \%$ was achieved in the 72 remaining patients who underwent primary surgery for microadenomas.

\section{DISCUSSION}

Transsphenoidal surgery for the treatment of pituitary tumors is a safe procedure in experienced hands.[1-3,11,13,14,23] The surgical mortality rate ranges from 0.4 to $2 \%,[3,11-14,17,22]$ and the single death in our series $(0.9 \%)$ is in keeping with this. The overall complication rate for transsphenoidal surgery accompanying pituitary adenomas is 3.3 to $9.3 \%,[2,3,14,17,19]$ and in this series it was $13.3 \%$, indicating that patients with Cushing's disease have a higher risk of complications than those with other pituitary adenomas.[6] However, if only the permanent complications are included, namely the patients with permanent DI and ocular neuropathy, then the rate is $1.8 \%$. The size of the tumor and previous surgery have been described as risk factors[3,13] in transsphenoidal surgery. In this series, however, only one of 27 patients who had previously undergone transsphenoidal surgery developed a complication. There was an increased incidence of complications in patients with macroadenomas (four of 13) or with normal MR images (four of 18), as compared with those patients with microadenomas (five of 74).

\section{Complications in This Series}

Diabetes Insipidus. Postoperatively, DI may be transient or permanent but only the permanent type is regarded as a complication, and it is rare, with a reported incidence of 0.5 to $15 \%$.[2,11] In this series it was $0.95 \%$. Transient DI occurs in 10 to $60 \%$ of reported cases and it occurred in $8.5 \%$ of our patients. Transient polyuria is frequently noted during the 1 st postoperative day, and usually only $20 \%$ of patients require treatment with desmopressin.[9] Early transient DI is thought to be caused by temporary dysfunction of vasopressin-producing neurons as a result of surgical trauma.[9]

Syndrome of Inappropriate Secretion of Antidiuretic Hormone. Typically, SIADH occurs 5 to 7 days postsurgery. One of the explanations for this phenomenon has been the release of stored ADH from the damaged posterior pituitary nerve terminals. $[3,4,9,10,20,24]$ In our series, the hyponatremia usually was transient and occurred in the first 2 days postsurgery in five cases, and 2 months later in one case. The very early postoperative hyponatremia is probably not SIADH, but is likely related to overhydration and hemodilution in the perioperative period.

Vascular Injury. Vascular injury occurring during transsphenoidal surgery is a rare yet potentially fatal complication and includes carotid artery (CA) rupture, CA cavernous fistulas, traumatic aneurysms, subarachnoid hemorrhage, CA vasospasm, and stroke.[2,3,11-13,16,17,19,21] Postoperative hemorrhage from the cavernous sinus, CA, or tumor bed can occur, causing visual deterioration or hypothalamic injury. Incidence of injury varies from 0.4 to $1.4 \%,[3]$ and there were no vascular injuries in this series.

Visual Complications. Optic nerve injury occurred in one patient in our series, and was thought to be caused by a misdirected approach and contusion of the optic nerve. The patient was treated with high-dose steroids, and the possibility of a fracture of the optic canal was excluded on CT scanning. Other possible causes of injury include vasospasm, a postoperative hematoma, or devascularization of the optic apparatus.[1] Delayed visual deterioration can also occur with the empty sella syndrome.[2]

Cranial Nerve Injuries. Injuries to the cranial nerves (excluding the second cranial nerve) usually occur as a result of exploration of the cavernous sinus for tumor, and the nerve most commonly injured is the sixth cranial nerve. $[3,13,17]$ The reported incidence is 0.4 to $1.9 \%$ and the injury may be temporary or permanent.[3] The single patient in our series who developed a transient third cranial nerve palsy was 
thought to have developed the complication as a result of our surgical exploration of the cavernous sinus.

Meningitis and CSF Leaks. A CSF leak may occur intra- or postoperatively and entails the risk of meningitis, which is a potentially fatal complication.[6,11] The reported incidence of CSF fistulas after transsphenoidal surgery is 1 to $4 \%$ and the incidence of meningitis is 0.8 to $2 \%$. A CSF leak that is recognized intraoperatively can be repaired by packing the sella and the sphenoid sinus with fat or muscle.[17] Meningitis may also occur without a postoperative CSF leak. Although a small percentage of these will resolve spontaneously, many will require operative repair,[12] as was the case in the patient in our series who developed a postoperative CSF leak. Prophylactic antibiotic drugs are used by most surgeons in an attempt to prevent meningitis but the effectiveness of these prophylactic medications has never been proven.[5,7,12,15,25]

Nasal Complications. Problems related to the nasal aspects of the operation are rarely fatal but may produce significant discomfort and distress, and include sinusitis (1-15\%), septal perforations (0.3-0\%), and epistaxis $(0.4-4.3 \%)$. [2,3,12,17] Nasal septal perforation can lead to chronic infection and may require secondary surgical repair. Nasal tip deformities or a saddle nose may occur when the nasal spine or cartilage is too aggressively removed. Postoperative sinusitis may require additional medical or surgical treatment. The two patients with nasal septal perforation in this series were asymptomatic, and these complications were not clearly related to operative techniques. Epistaxis occurred in one of our patients 3 weeks postsurgery and required cauterization of the sphenopalatine artery. Epistaxis can be treated with nasal packing, cautery, or ligation/embolization of the internal maxillary artery.[2,3]

Medical Complications. Deep venous thrombosis and pulmonary emboli have been reported to occur with varying frequency after transsphenoidal surgery.[2,3,6] Fahlbusch, et al.,[6] reported four cases of deep venous thrombosis and pulmonary emboli in their series of 101 patients who underwent transsphenoidal operations for Cushing's disease. The two operative deaths in the report published by Ciric, et al.,[3] were caused by pulmonary emboli. In our series, four patients (3.8\%) developed deep vein thrombosis between 2 and 4 weeks postsurgery.[3] None developed a pulmonary embolus. We postulate that the obesity associated with Cushing's disease and the consequent relative immobility of these patients, together with the hypercoagulable state postsurgery may be responsible for the relatively high incidence of deep vein thrombosis in patients with Cushing's disease. Our standard procedure had been to use elastic stockings and early mobilization to prevent these complications. We have since developed a policy of administering postoperative aspirin therapy to patients with Cushing's disease.

Pneumonia was the cause of death in two patients treated for Cushing's disease by Fahlbusch, et al.[6] There was one patient in our series who developed pneumonia and a urinary tract infection requiring hospitalization and medical treatment. One patient had dehiscence of the abdominal fat graft wound; poor healing is characteristic of the hypercortisolemic state. Patients with Cushing's disease are frequently debilitated because of associated medical conditions such as obesity, hypertension, and diabetes mellitus, which render them more susceptible to infections in the postoperative period.

\section{CONCLUSIONS}

Transsphenoidal surgery remains a safe procedure for the treatment of patients with Cushing's disease. The surgical complications and mortality rates are comparable to those found in more general series of patients undergoing transsphenoidal surgery for pituitary adenomas. In our series the complication rate (13.3\%) is higher than those in other published series of transsphenoidal microsurgery for pituitary adenomas in general $(3.5-9.3 \%),[2,3,12,18,23]$ although the incidence of serious complications causing 
permanent morbidity is low (1.8\%). We believe that this elevation of the complication rate in our series is related to the increased occurrence of medical problems, namely deep vein thrombosis (and the life-threatening risk of pulmonary embolus), pneumonia, and poor wound healing in patients with Cushing's disease. Because there is a definite risk of deep vein thrombosis that can be life threatening in these patients, we believe that they should undergo prophylactic therapy for this complication during the perioperative period.[8]

\section{References}

1. Barrow DL, Tindall GT: Loss of vision after transsphenoidal surgery. Neurosurgery 27:60-68, 1990

2. Black PM, Zervas NT, Candia GL: Incidence and management of complications of transsphenoidal operation for pituitary adenomas. Neurosurgery 20:920-924, 1987

3. Ciric I, Ragin A, Baumgartner C, et al: Complications of transsphenoidal surgery: results of a national survey, review of the literature, and personal experience. Neurosurgery 40:225-237, 1997

4. Cusick JF, Hagen TC, Findling JW: Inappropriate secretion of antidiuretic hormone after transsphenoidal surgery for pituitary tumors. N Engl J Med 311:36-38, 1984

5. Eljamel MS: Antibiotic prophylaxis in unrepaired CSF fistulae. Br J Neurosurg 7:501-506, 1993

6. Fahlbusch R, Buchfelder M, Müller OA: Transsphenoidal surgery for Cushing's disease. J R Soc Med 79:262-269, 1986

7. Haile-Mariam T, Laws ER Jr, Tuazon CU: Gram-negative meningitis associated with transsphenoidal surgery: case reports and review. Clin Inf Dis 18:553-556, 1994

8. Hamilton MG, Hull RD, Pineo GF: Venous thromboembolism in neurosurgery and neurology patients: a review. Neurosurgery 34:280-296, 1994

9. Hensen J, Buchfelder M, Henig A, et al: Disturbances of osmoregulation in the neurosurgical setting--with special emphasis on the situation after surgery for pituitary tumors, in von Werder K, Fahlbusch R (eds): Pituitary Adenomas: From Basic Research to Diagnosic and Therapy. Amsterdam: Elsevier, 1996, pp 255-268

10. Kelly DF, Laws ER Jr, Fossett D: Delayed hyponatremia after transsphenoidal surgery for pituitary adenoma. Report of nine cases. J Neurosurg 83:363-367, 1995

11. Landolt AM: Transsphenoidal surgery of pituitary tumors: its pitfalls and complications, in de Villiers JC (ed): Some Pitfalls and Problems in Neurosurgery. Progress in Neurological Surgery, Vol 13. Basel: Karger, 1990, pp 1-30

12. Laws ER Jr: Complications of surgery for ACTH secreting tumors, in Lüdecke DK, Chrousus GP, Tolis G (eds): ACTH, Cushing's Syndrome, and Other Hypercortisolemic States. Progress in Endocrine Research and Therapy, Vol 5. New York: Raven Press, 1990, pp 275-280

13. Laws ER Jr: Complications of transsphenoidal microsurgery for pituitary adenomas. Mod Neurosurg 1:181-185, 1982

14. Laws ER Jr: Pituitary surgery. Endocrinol Metab Clin North Am 16:647-665, 1987 
15. Laws ER Jr, Abboud CF, Kern EB: Perioperative management of patients with pituitary microadenoma. Neurosurgery 7:566-570, 1980

16. Laws ER Jr, Kern EB: Complications of transsphenoidal surgery, in Laws ER Jr, Randall RV, Kern EB, et al (eds): Management of Pituitary Adenomas and Related Lesions with Emphasis on Transsphenoidal Microsurgery. New York: Appleton-Century-Crofts, 1982, pp 329-346

17. Laws ER Jr, Thapar K: Surgical management of pituitary adenomas. Baillieres Clin Endocrinol Metab 9:391-405, 1995

18. Mampalam TJ, Tyrrell JB, Wilson CB: Transsphenoidal microsurgery for Cushing's disease. A report of 216 cases. Ann Intern Med 109:487-493, 1988

19. Matsuno A, Yoshida S, Basugi N, et al: Severe subarachnoid hemorrhage during transsphenoidal surgery for pituitary adenoma. Surg Neurol 39:276-278, 1993

20. Murty GE, Lamballe P, Welch AR: Early inappropriate secretion of antidiuretic hormone after trans-sphenoidal pituitary adenomectomy. J Laryngol Otol 104:894-895, 1990

21. Raymond J, Hardy J, Czepko R, et al: Arterial injuries in transsphenoidal surgery for pituitary adenoma: the role of angiography and endovascular treatment. AJNR 18:655-665, 1997

22. Sheeler LR: Cushing's syndrome--1988. Cleve Clin J Med 55:329-337, 1988

23. Thapar K, Laws EB: Complications and outcome of transsphenoidal microsurgery in ACTH-secreting adenomas. J Neurosurg 76:372A, 1992 (Abstract)

24. Ultmann MC, Hoffman GE, Nelson PB, et al: Transient hyponatremia after damage to the neurohypophyseal tracts. Neuroendocrinology 56:803-811, 1992

25. Van Aken MO, de Marie S, van der Lely AJ, et al: Risk factors for meningitis after transsphenoidal surgery. Clin Infect Dis 25:852-856, 1997

Manuscript received June 8, 1998.

Accepted in final form March 29, 1999.

Address reprint requests to: Edward R. Laws, Jr., M.D., Department of Neurological Surgery, University of Virginia Health Sciences Center, Box 212, Charlottesville, Virginia 22908. 